\title{
Analysis of Load flow and Transient stability of 10-bus multi-machine system with $P V$ penetration
}

\author{
Sarah Alasady ${ }^{1}$, Rasheed Almansory ${ }^{2}$, and Haider Alrudainy ${ }^{3}$ \\ \{yaramn8@gamil.com ${ }^{1}$, r.s.almansory@stu.edu.iq ${ }^{2}$, and h.m.a.alrudainy@ stu.edu.iq ${ }^{3}$ \} \\ Southern Technical University, Technical Engineering College, Iraq, Basra ${ }^{1,2,3}$
}

\begin{abstract}
The increasing importance of solar energy to support and stabilize electrical power networks and reduce dependence on fossil fuels has recently received remarkable attention. This research deals with the analysis of the load flow and transient state stability of a network consists of 10-bus with solar cells using the ETAP software toolbox. Further, Transient stability analysis is presented in this paper for the design of the proposed power system with grid-connected photovoltaic (PV) systems under large perturbations (middle of transmission line fault), Integrating PV generations at bad locations can cause serious degradation to system Transient stability, Selecting the location of solar energy in the network and its size has a beneficial effect on the stability of the network, the analysis demonstrates that photovoltaic (PV) power system facilitated sustain stability and drastically enhance the reliability of the examined system, thus having an advantageous influence on the electric power system.
\end{abstract}

Keywords: Photovoltaic, power grid, transient stability analysis, load flow analysis, threephase fault, IEEE 10 bus system, ETAP.

\section{Introduction}

In recent years, owing to their ecological operations and considerably fluctuated prices of fossil fuels, sustainable energy sources worldwide have gained remarkable attention. The photovoltaic (PV) system produces electricity from naturally available sunlight and is becoming one of the most common (Renewable Energy Sources) RES systems. Two modes of use, standalone and grid-connected, are more convenient in the literature as this reduces the costs of building power storage than the first. Furthermore, there are initiatives motivating governments of some countries to integrate network-connected photovoltaic (PV) systems. Accordingly, these have led in recent years to the emergence of more PV systems on the rooftop [1][2].

The implementation of PV generators however affects electricity systems' efficiency. PV penetration degrades power systems' reliability, for instance, because PV generators have no synchronizing time torque; for example, an internal torque to maintain generator synchronization. A lot of studies have been carried out to date to solve this issue. A PV model for the interaction of PV generators with power systems was designed, for example. The effects of photovoltaic (PV) penetration on the voltage properties and transient stability of the electric power systems have been studied by other researchers. The controller architecture has also been implemented for photovoltaic (PV) systems linked to the power network [3].

Another paper,[4] addressed the influence of a grid-connected photovoltaic (PV) system on the stability of dynamic and static voltage. This work shows that the PV system impacts the reliability of the distribution and transmission systems rely on factors such as temperature, 
shading effect, photovoltaic latitude, and the form of photovoltaic plant integration at different degrees of penetration. Moreover, work in [5] has addressed minor signal disorders in a standalone environment that is not incorporated into the electrical power grid for the transient reliability of a PV-diesel hybrid system. In [6] the impact of PV systems has been shown on short-term voltage stability and the findings of the study suggest that short-term voltage stability was severely affected when voltage sage and the PV system were disconnected.

The integration of solar photovoltaic power in a 10-bus electricity grid was simulated and investigated to explore the effect stability of solar cells on the network. Our model was established by using Electrical Transient Analyses (ETAP) simulation tool which is an extensive framework for the study of generation, transmission, delivery, industry, and industrial energy systems for the architecture, simulation, operation, controls, automation, and optimization.

\section{Load Flow and System Stability}

\subsection{Power System Stability}

The stability of the electric power system is interpreted as follows based on the description in the well-known report [7]. Power system stability (PSS) can be defined as the capability of an electric power system, for a particular initial working condition, to retrieve the equilibrium condition after being exposed to a physical disturbance, with major system variables reduced to allow the whole system to remain practically unchanged. The categorization of power system stability can be seen as illustrated in Fig. 1.

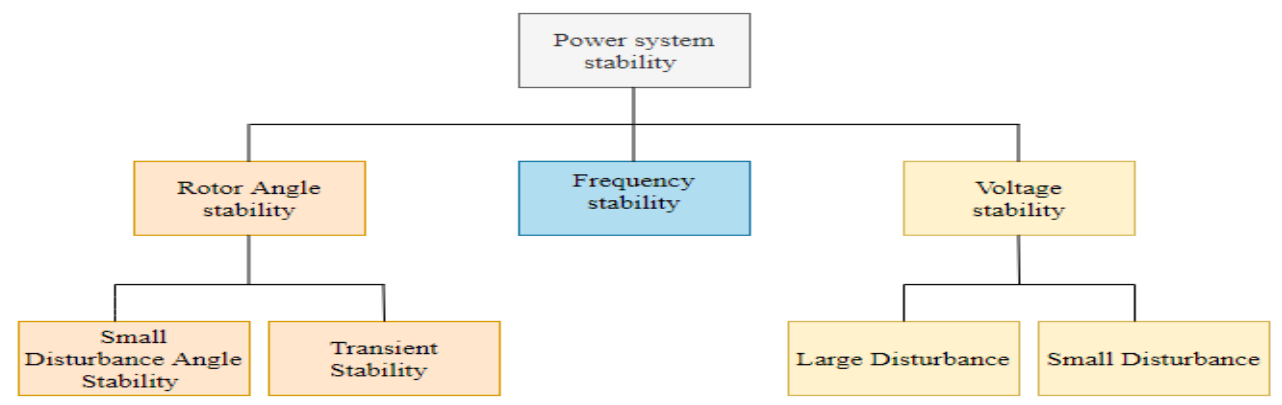

Fig. 1. Shows the types of power system stability.

Transient Stability: Transient stability can be explained as the capability of the electric power system to preserve synchronism throughout large disturbances [7]. Such disruptions might include a failure of a bus or the transmission line, equipment, loss of a large load, and generation. The study discussed in this section aims to analyze whether such great system turbulence has an effect on the system with PV penetration, a technique known as the Equal-area criterion can be adopted. This approach has relied on the graphical representation of the energy contained in the spinning mass to help to regulate if the machine is stable after a perturbation. This approach applies only to a one-machine system that is connected to an endless bus or two-machine system.

Consider the swing equation: 
$M \frac{d^{2} \delta_{m}}{d t^{2}}=P_{m}-P_{e}$

Where $\mathrm{M}$ is inertia constant. It is considered not constant when the rotor velocity drifts from the synchronous speed.

$\mathrm{p}_{\mathrm{m}}=$ Shaft power input.

$\mathrm{p}_{\mathrm{e}}=$ electical power output.

$\delta_{\mathrm{m}}=$ mechanical power angle

$\frac{\mathrm{d}^{2} \delta}{\mathrm{d} t^{2}}=\frac{1}{M}\left(P_{m}-P_{e}\right)=\frac{P_{a}}{M}$.

Where $\mathrm{p}_{\mathrm{a}}$ is the acceleration power

$M=\frac{H}{\pi f}$ in pu system.

$\frac{d^{2} \delta}{d t^{2}}=\frac{\pi f}{H}\left(P_{m}-P_{e}\right)$

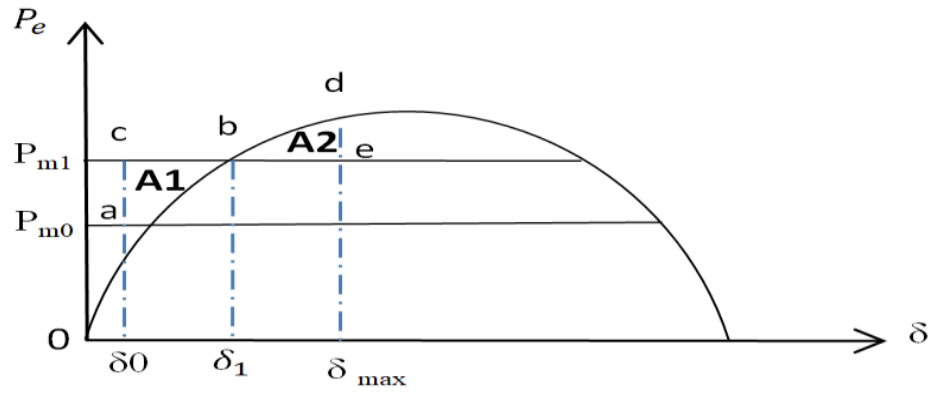

Fig. 2. Demonstrates the equal-area criterion.

Consider the machine working at the equilibrium point $\delta 0$, which is the mechanical input power $\mathrm{P}_{\mathrm{m} 0}=\mathrm{P}_{\mathrm{e} 0}$ as shown in fig. 2 . Take into consideration a sudden rise in the input power of horizontal line $\mathrm{P}_{\mathrm{m} 1}$. Since $\mathrm{P}_{\mathrm{m} 1}>\mathrm{P}_{\mathrm{e} 0}$, the rotor is accelerating positively, increasing the power angle $\delta$. The amount of excess energy saved at first acceleration in the rotor is:

$\int_{\delta_{0}}^{\delta_{1}}\left(P_{m 1}-P_{e}\right) d \delta=$ area $a b c=$ area $A_{1}$. (Accelerating Area)

The rotor shall swing past point $\mathrm{b}$ until the rotating masses give up the same amount of energy. The energy the rotor gives when it slows down to synchronous speed is,

$\int_{\delta_{1}}^{\delta_{\max }}\left(P e-P_{m 1}\right) d \delta=$ area $b d e$

$=\operatorname{area} A_{2} \cdot($ Decelarating Area) 
For stability, the area under the graph must be zero against $\delta$; i.e. the graph's positive (accelerating) area must be equal to the negative (decelerating) area. This criterion is thus wellknown as the equal-area principle for stability. This can be illustrated in Fig.2.

As a consequence, the rotor swings to $b$ and $\delta_{\max }$ at which point.

|the area $A_{1}|=|$ area $A_{2} \mid$.

This is well-known as the equal-area principle. Then at its normal frequency, the rotor angle can oscillate back and forth between $\delta_{0}$ and $\delta_{\max }$. The damping in the system would result in the subsidizing of these oscillations and the new steady-state operating point would be settled at point $\mathrm{b}[8]$.

\subsection{Load Flow Analysis}

Studies of power flow, usually called load flow, constitute an essential part of the study of energy systems. They are needed for the preparation, financial planning, control, and potential expansion of existing systems. The problem is to estimate the voltages and phase angle of each bus and active and reactive power flows for each line. The device is assumed to work in balanced conditions in solving a power flow problem and is applied with one-step models. Each bus is linked to four amounts including phase angle, voltage magnitude, reactive power, and a real power. In general, systems buses are divided into three types:- slack buses, load buses, Regulated buses [9].

i) Flow Calculation Methods

Four methods of load flow calculations: Newton-Raphson, Adaptive Newton-Raphson, Accelerated Gauss-Seidel, and Fast-Decoupled. All four diverse ways of measuring load flow have various convergence requirements that each should be. to produce optimal results and fewer errors in a given situation. Any of these methods can be chosen depending on the topology of the structure, type of generation, loading status, and the initial value of the bus voltages.

ii) Accelerated Gauss-Seidel Method

We can write the system nodal voltage equation as:

$[I]=\left[Y_{B U S}\right][V]$.

The Gauss-Seidel accelerated technique adopts the load flow equation and iterations to produce the following results:

$[P+j Q]=\left[V^{T}\right]\left[Y_{B U S}^{*}\right]\left[V^{*}\right]$

where $\mathrm{P}$ and $\mathrm{Q}$ are the true and reactive bus power vectors, $\mathrm{Y}_{\mathrm{BUS}}$ is the electrical system's entry matrix, and $\mathrm{V}$ is the bus voltage vector. $\mathrm{V}^{*}$ and $\mathrm{Y}^{*}{ }_{\mathrm{BUS}}$ are the $\mathrm{V}$ conjugates and $\mathrm{Y}_{\mathrm{BU}}$ respectively. $\mathrm{V}^{\mathrm{T}}$ is the transposed $\mathrm{V}$ matrix that is the bus stress.

\section{Analysis of Case Studies}

3.1 Power System Model with PV Penetration 
In this section, a simple test system is introduced. This test system is used to present fundamental concepts and principles of power system stability, specifically Transient stability, considering a penetration level of PV generation. The stability of the test system is studied in response to large disturbances; for example, severe system faults. The considered test system is based on an adapted for the specific needs to study Transient stability.

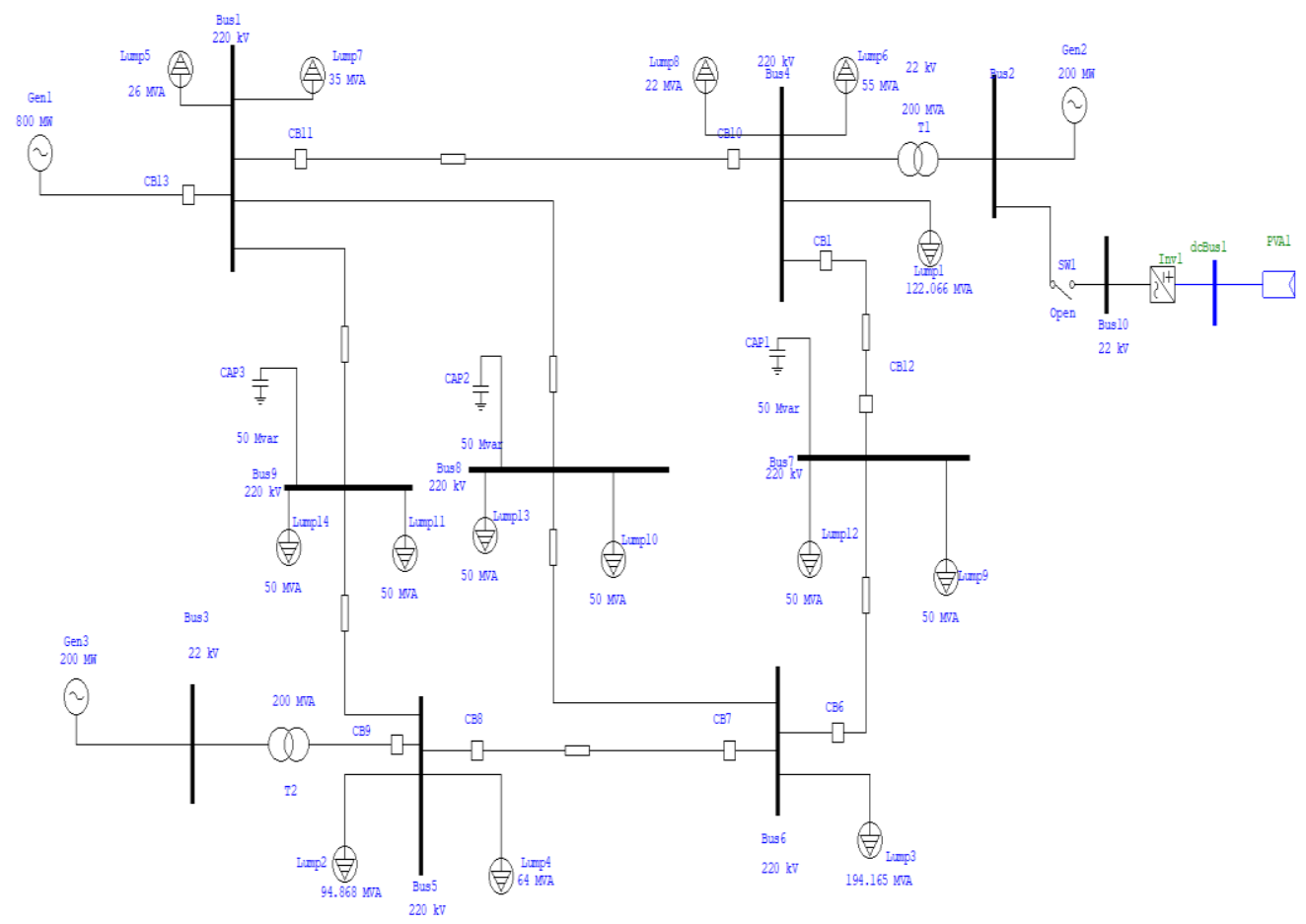

Fig. 3. Indicates the single-line illustration of the IEEE10-Bus system with the photovoltaic array.

Table 1. Shows the generator data of the IEEE10 Bus system.

\begin{tabular}{|c|c|c|c|c|c|c|c|c|}
\hline \multirow{8}{*}{ 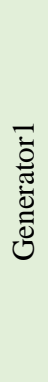 } & \multicolumn{2}{|c|}{ Model } & Value & \multirow{8}{*}{ 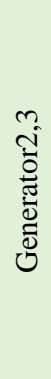 } & \multicolumn{2}{|c|}{ Model } & \multirow{2}{*}{$\begin{array}{c}\text { Value2 } \\
----\end{array}$} & \multirow{2}{*}{$\begin{array}{l}\text { Value3 } \\
-----~\end{array}$} \\
\hline & Operation mode & Swing & --------- & & Oper. mode & $\begin{array}{l}\text { Voltage } \\
\text { control }\end{array}$ & & \\
\hline & \multirow[t]{2}{*}{ Rating } & MVA & 941.176 & & \multirow[t]{2}{*}{ Rating } & MVA & 235.29 & 235.29 \\
\hline & & $\mathrm{KV}$ & 220 & & & KV & 22 & 22 \\
\hline & Imp/model & $\mathrm{x}_{\mathrm{d}} "$ & 12 & & Imp/model & xd " & 12 & 12 \\
\hline & \multirow{3}{*}{ Inertia } & RPM & 1500 & & \multirow{3}{*}{ Inertia } & RPM & 1500 & 1500 \\
\hline & & $\mathrm{WR}^{2}$ & 1524975 & & & $\mathrm{WR}^{2}$ & 76249 & 56043 \\
\hline & & $\mathrm{H}$ & 20 & & & $\mathrm{H}$ & 4 & 2.10 \\
\hline
\end{tabular}


Table 2. Data of PV Array.

\begin{tabular}{|l|l|l|}
\hline \multirow{4}{*}{} & Rated power (kW) & 240 \\
\cline { 2 - 3 } & No.of modules & 2800 \\
\cline { 2 - 3 } & The voltage at max. power (Vmp) & 17.93 \\
\cline { 2 - 3 } & Current at max. power (Imp) & 4.78 \\
\cline { 2 - 3 } & Open circuit voltage (Voc) & 22.04 \\
\cline { 2 - 3 } & Short circuit current (Ioc) & 5.18 \\
\cline { 2 - 3 } & Total number of cells in series (Ns) & 100 \\
\cline { 2 - 3 } & Total number of cells in parallel (Np) & 28 \\
\cline { 2 - 3 } & PV cell type & Multi-crystalline \\
\hline \multirow{5}{*}{} & Number of units & 1 \\
\cline { 2 - 3 } & Rated capacity & $240 \mathrm{~kW}$ \\
\cline { 2 - 3 } & Input DC Volt & $22 \mathrm{~V}$ \\
\cline { 2 - 3 } & Output voltage & $22 \mathrm{~V}$ \\
\cline { 2 - 3 } & Frequency & $50 \mathrm{HZ}$ \\
\hline
\end{tabular}

The single-line diagram of the 10-bus test system is depicted in Fig.3 For this study the original test system a slightly modified IEEE-6 bus system is considered[10]. in this paper, a typical 10bus system comprises three generators connected to a network of three different busses. Generator 1 is known as the swing bus, Generator 2 and Generator 3 are considered to be the form of the voltage control, bus It has 14 loading points, also, a generator PV has been added on bus No. 2. Penetration PV injects a great deal of energy through the system that affects all existing buses' active and reactive capacity. Results included in this work are estimated by using ETAP (power system analysis software). The main part of this paper is to study the impact of the PV plants on the performance of the grid. The validated model has been used to study and analyze the impact of the planned PV power plants on the transient stability of the power system. Moreover, the combination with PV solar to improve the overall stability of the system will be considered in the research plane.

\subsection{Load Flow Results}

Results of the load flow obtained from the IEEE 10-bus power grid with the photovoltaic (PV) systems are used in load-flow analysis to guarantee that electrical power transfer from generators to consumers through the network is reliable and stable, Due to its active power generation and voltage control. There may be several load flow cases to be studied relying on the kind of plant. The aim is to determine the worst and best working conditions. Various load flow solution algorithms are utilized in the industry such as Newton-Raphson, Gauss-Seidel, and current injection. Thus, The basic load flow results for an IEEE 10 bus system without and with the photovoltaic (PV) power system are illustrated (in Table.3 and Table.4), The Standard Newton-Raphson Method.

Table 3. Load-flow results of the IEEE 10 bus network without an PV system.

\begin{tabular}{|l|l|l|l|l}
\hline Bus & Voltage & Generation & Load & Load flow \\
\hline
\end{tabular}




\begin{tabular}{|c|c|c|c|c|c|c|c|c|c|c|c|}
\hline ID & KV & \%Mag. & Ang. & MW & Mvar & MW & Mvar & ID & MW & Wvar & Amp \\
\hline \multirow[t]{3}{*}{ Bus1 } & \multirow[t]{3}{*}{220} & \multirow[t]{3}{*}{106} & \multirow[t]{3}{*}{0.0} & \multirow{3}{*}{$\begin{array}{l}568.6 \\
36\end{array}$} & \multirow[t]{3}{*}{181.889} & \multirow[t]{3}{*}{51.850} & \multirow[t]{3}{*}{32.134} & Bus4 & 155.492 & 34.864 & 394.5 \\
\hline & & & & & & & & Bus9 & 213.274 & 34.600 & 534.9 \\
\hline & & & & & & & & Bus8 & 148.020 & 80.291 & 416.9 \\
\hline Bus2 & 22 & 104 & -16.8 & 150 & 220.887 & 0 & 0 & Bus4 & 150.000 & 220.887 & 6737.5 \\
\hline Bus3 & 22 & 103 & -17.8 & 100 & 177.351 & 0 & 0 & Bus5 & 100.000 & 177.351 & 5187.5 \\
\hline \multirow[t]{3}{*}{ Bus4 } & \multirow[t]{3}{*}{220} & \multirow[t]{3}{*}{98.667} & \multirow[t]{3}{*}{-18.8} & & \multirow[t]{3}{*}{0} & \multirow{3}{*}{$\begin{array}{l}165.45 \\
0\end{array}$} & \multirow[t]{3}{*}{110} & Bus1 & -147.574 & 15.355 & 394.6 \\
\hline & & & & & & & & Bus7 & 131.732 & 78.496 & 407.9 \\
\hline & & & & & & & & Bus2 & -149.608 & -204.414 & $\begin{array}{ll}673.8 \\
\end{array}$ \\
\hline \multirow[t]{3}{*}{ Bus5 } & \multirow[t]{3}{*}{220} & \multirow[t]{3}{*}{98.675} & \multirow[t]{3}{*}{-19.2} & \multirow[t]{3}{*}{0} & \multirow[t]{3}{*}{0} & \multirow{3}{*}{$\begin{array}{l}144.40 \\
0\end{array}$} & \multirow[t]{3}{*}{63.714} & Bus6 & 69.753 & 77.835 & 278.0 \\
\hline & & & & & & & & Bus9 & -114.349 & 26.036 & 311.9 \\
\hline & & & & & & & & Bus3 & -99.805 & -167.584 & 518.8 \\
\hline \multirow[t]{3}{*}{ Bus6 } & \multirow[t]{3}{*}{220} & \multirow[t]{3}{*}{83.643} & \multirow[t]{3}{*}{-26.2} & \multirow[t]{3}{*}{0} & \multirow[t]{3}{*}{0} & \multirow{3}{*}{$\begin{array}{l}160.00 \\
0\end{array}$} & \multirow{3}{*}{$\begin{array}{l}110.00 \\
0\end{array}$} & Bus5 & -66.830 & -58.438 & 278.5 \\
\hline & & & & & & & & Bus7 & -41.786 & -46.583 & 196.3 \\
\hline & & & & & & & & Bus8 & -51.385 & -4.979 & 162.0 \\
\hline \multirow[t]{2}{*}{ Bus7 } & \multirow[t]{2}{*}{220} & 92.105 & -23.3 & 0 & 0 & 85.000 & 10.262 & Bus4 & -128.348 & -63.551 & 408.1 \\
\hline & & & & & & & & Bus6 & 43.348 & 53.289 & 195.7 \\
\hline Bus8 & 220 & 88.290 & -17.8 & 0 & 0 & 85.000 & 13.703 & Bus1 & -137.908 & -26.459 & 417.4 \\
\hline & & & & & & & & Bus6 & 52.908 & 12.757 & 161.8 \\
\hline Bus9 & 220 & 99.609 & -11.8 & 0 & 0 & 85.000 & 3.069 & Bus1 & -202.883 & 8.565 & 535.0 \\
\hline & & & & & & & & Bus5 & 117.883 & -11.634 & 312.1 \\
\hline
\end{tabular}

Table 4. Load-flow results of the IEEE 10 bus network with an PV system.

\begin{tabular}{|c|c|c|c|c|c|c|c|c|c|c|c|}
\hline \multicolumn{2}{|l|}{ Bus } & \multicolumn{2}{|l|}{ Voltage } & \multicolumn{2}{|c|}{ Generation } & \multicolumn{2}{|l|}{ Load } & \multicolumn{4}{|c|}{ Load flow } \\
\hline ID & KV & $\% \mathrm{Mag}$. & Ang. & MW & Mvar & MW & Mvar & ID & MW & Wvar & Amp \\
\hline \multirow[t]{3}{*}{ Bus1 } & \multirow[t]{3}{*}{220} & \multirow[t]{3}{*}{106} & \multirow[t]{3}{*}{0.0} & \multirow{3}{*}{$\begin{array}{l}570.6 \\
1\end{array}$} & \multirow[t]{3}{*}{207.54} & \multirow[t]{3}{*}{51.850} & \multirow[t]{3}{*}{32.133} & Bus4 & 153.428 & 51.650 & 400.8 \\
\hline & & & & & & & & Bus9 & 215.918 & 36.487 & 542.1 \\
\hline & & & & & & & & Blus8 & 149.049 & 87.277 & 427.6 \\
\hline \multirow[t]{2}{*}{ Bus2 } & \multirow[t]{2}{*}{22} & \multirow[t]{2}{*}{100} & \multirow[t]{2}{*}{-16.8} & \multirow[t]{2}{*}{150} & \multirow[t]{2}{*}{197.68} & \multirow[t]{2}{*}{0} & \multirow[t]{2}{*}{0} & Bus4 & 150.000 & 197.686 & 6512.3 \\
\hline & & & & & & & & Bus10 & -0.238 & 2.437 & 5571.9 \\
\hline Bus3 & 22 & 103 & -18.1 & 100 & 188.81 & 0 & 0 & Bus5 & 100.000 & 188.815 & 5443.8 \\
\hline
\end{tabular}




\begin{tabular}{|c|c|c|c|c|c|c|c|c|c|c|c|}
\hline \multirow[t]{3}{*}{ Bus4 } & \multirow[t]{3}{*}{220} & \multirow[t]{3}{*}{95.03} & \multirow[t]{3}{*}{-18.9} & & \multirow[t]{3}{*}{0} & \multirow[t]{3}{*}{165.4} & \multirow[t]{3}{*}{110} & Bus1 & -145.253 & 0.249 & 401.1 \\
\hline & & & & & & & & Bus7 & 129.436 & 71.485 & 408.3 \\
\hline & & & & & & & & Bus2 & -149.634 & -182.295 & 651.2 \\
\hline \multirow[t]{3}{*}{ Bus5 } & \multirow[t]{3}{*}{220} & \multirow[t]{3}{*}{98.39} & \multirow[t]{3}{*}{-19.5} & \multirow[t]{3}{*}{0} & \multirow[t]{3}{*}{0} & \multirow[t]{3}{*}{144.40} & \multirow[t]{3}{*}{63.71} & Bus6 & 71.941 & 88.164 & 303.5 \\
\hline & & & & & & & & Bus9 & -116.556 & 26.182 & 318.6 \\
\hline & & & & & & & & Bus3 & -99.785 & -178.060 & 544.4 \\
\hline \multirow[t]{3}{*}{ Bus6 } & \multirow[t]{3}{*}{220} & \multirow[t]{3}{*}{81.46} & \multirow[t]{3}{*}{-26.9} & \multirow[t]{3}{*}{0} & \multirow[t]{3}{*}{0} & \multirow[t]{3}{*}{159.99} & \multirow[t]{3}{*}{109.99} & Bus5 & -68.456 & $\begin{array}{l}-64.984 \\
\end{array}$ & 304.1 \\
\hline & & & & & & & & Bus7 & -39.779 & -37.792 & 176.8 \\
\hline & & & & & & & & Bus8 & -51.763 & -7.224 & 168.4 \\
\hline \multirow[t]{2}{*}{ Bus7 } & \multirow[t]{2}{*}{220} & \multirow[t]{2}{*}{88.74} & \multirow[t]{2}{*}{-23.8} & \multirow[t]{2}{*}{0} & \multirow[t]{2}{*}{0} & \multirow[t]{2}{*}{85} & \multirow[t]{2}{*}{13.30} & Bus4 & -126.046 & -56.496 & 408.5 \\
\hline & & & & & & & & Bus6 & 41.046 & 43.192 & 176.2 \\
\hline \multirow[t]{2}{*}{ Bus8 } & \multirow[t]{2}{*}{220} & \multirow[t]{2}{*}{86.88} & \multirow[t]{2}{*}{-18.1} & 0 & 0 & 85 & 14.93 & Bus1 & -138.409 & -30.605 & 428.1 \\
\hline & & & & & & & & Bus6 & 53.408 & 15.675 & 168.1 \\
\hline Bus9 & 220 & 99.41 & -11.9 & 0 & 0 & 85 & 3.267 & Bus1 & -205.244 & 7.866 & 542.2 \\
\hline & & & & & & & & Bus5 & 120.244 & -11.133 & 318.8 \\
\hline Bus10 & 22 & 100 & -16.8 & 0.238 & 2.437 & 0 & 0 & Bus2 & 0.238 & 2.437 & 5571.9 \\
\hline
\end{tabular}

Table 3 without a PV system shows the load flow effects under normal operating conditions. Under these conditions, the generator connected to a slack bus requires a considerable amount of reactive power, which is much more than the reactive power taken from the device loads (343.44 MVAR). Table 4 shows the outcomes and effects of the PV system, Under these conditions, the output of reactive power is decreased. In the network, the PV bus draws (2.437 MVAR) reactive capacity. Increased PV capacity penetration replaces the peak load value by load demand throughout the day. The contribution of photovoltaic to the highest load reduction is therefore excessive and necessities to be adjusted to the changed situation of demand with a new increase in PV power.

\section{Simulation Results of Transient Stability}

For designing, simulating, automating of generation, distribution of industrial power systems, and ETAP comprehensive toolbox analysis platform has been used. The IEEE 10-bus system has been investigated and the photovoltaic grid is connected to the power supply as indicated in Fig.3. A comprehensive simulation analysis was performed to estimate the impact of the PV on the transient stability of a power system, based on observing the electrical grid terminal voltage, generator velocity, rotor angle, and power production. A power system disruption is abrupt variations in one or more elements of the power system or a series of changes. The presence of a fault on line 1 in the IEEE 10 bus network is a major disturbance. The key problem was the dissemination of active power of the photovoltaic power system to the network to compensate for the rapid shift in the electrical power grid. Some of these case studies are investigated as can be seen below.

\subsection{Simulation Results in the Case Without PV Implemented}

The influence of PV on the IEEE-10 bus system was examined on two criteria: the first was without PV connection and the second was PV connection; Concerning transient stability, major disruptions like a three-phase fault occur, The impact on the power system transient 
performance owning to line fault taking place in it without photovoltaic (PV) set up has been investigated. A fault has been placed at line1 at "9.00 second", and it is then cleared at "9.12 second". The electrical power, bus voltages, terminal current of the generator have been noted and plotted for a "100second" period, as indicated in Fig. 4. The voltages at bus 1 and bus 5 are plotted. In this study, both voltages have been investigated as bus 1 is close to a fault and bus 5 is a little far away from the fault. The oscillations after the fault for the base case are minute and converging to a stable value. The oscillations case was relative with higher amplitude, and it was maintaining irregular value. The voltage dips are very high. But it was maintaining stabilized value after a while, The results of the simulation show that the system is stable, and the generator is synchronized with the network.
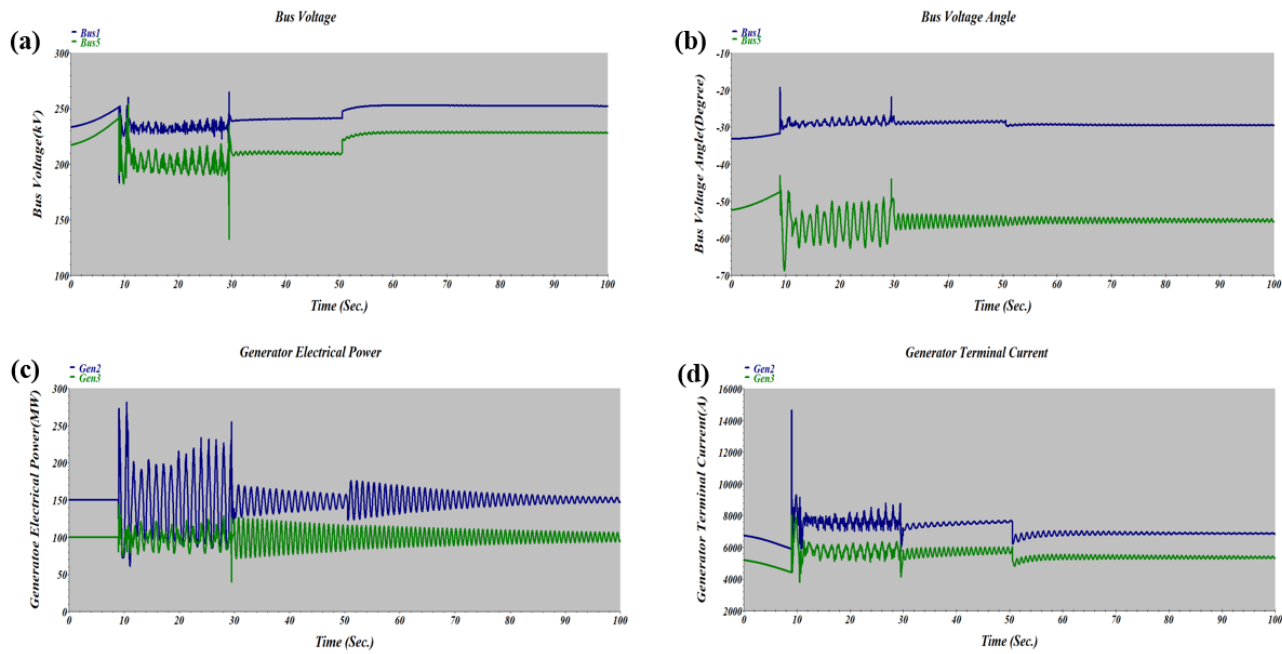

Fig. 4. IEEE 10 bus network simulation results without the photovoltaic power system: (a) voltage of the bus; (b) angle of voltage; (c)electrical power; (d) current terminal.

\subsection{Simulation Results In The Case With PV Implemented}

Most PVs are designed so that immediately after a major disruption the system is disconnected, particularly when a system fault happens in or near the photovoltaic power plant. Solar PV plant has been integrated into bus 2 of the IEEE 10-bus system, as described in the previous section. The same system that was used previously for steady-state analysis has been considered for transient analysis too. The "Transient Stability Analysis" module of the ETAP has been used for the simulation and analysis. The results show that the power system is much more stable with a PV system, to investigate the ideal position of the solar generator and maximum safe instantaneous penetration in the event of large disturbances, considering the stability of the system and its safety limits. Furthermore, the PV penetration increases and this contribution is more essential. These plants can contribute to the system control and stability similarly to traditional producing units if a certain level of active power reserve or storage is given, as shown in Fig. 5. 

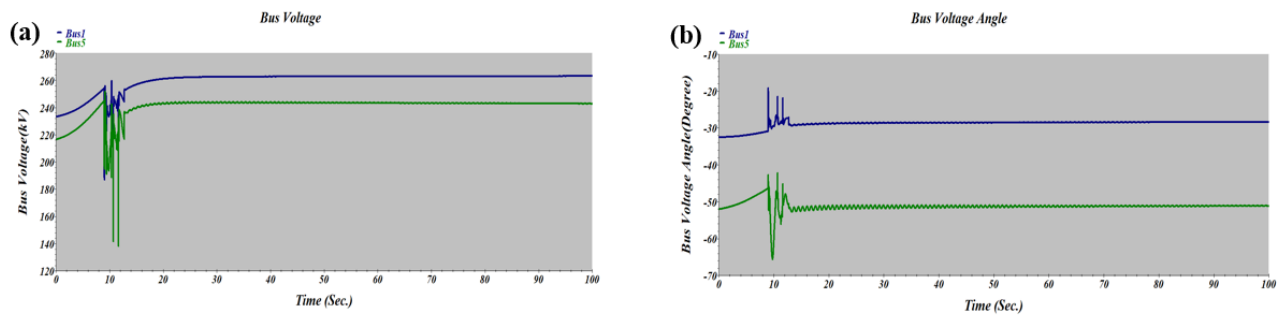

(c)
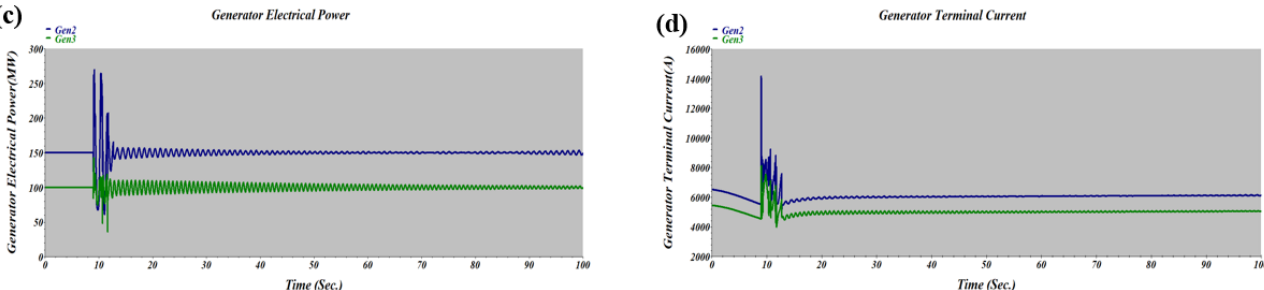

Fig. 5. IEEE 10 bus network simulation results with the photovoltaic plant : (a) voltage of the bus; (b) angle of voltage; (c) electrical power; (d) current terminal.

\section{Conclusion}

This paper provides a case study evaluating the effect of PV power permeation on steady-state and transient power system stability on the grid. Considering the Original IEEE 10 bus and the photovoltaic system of the electric power system, simulation analyzes were carried out. Results of the simulation study show the reliability and stability of test systems are maintained by the PV system penetration. By improving the voltage stability of the power grid under a short circuit middle of line1 (between bus 1 and bus 4) with the PV system, reactive power compensation is increased via a PV system. The location of the fault and fault clearing time affect the stability of the voltage and Voltage instability is reasoned as one of the major threats to the secure operation of electric power systems around the globe. Thus, the PV panel connected to the grid impacts the stability of the power system.

\section{References}

[1] M. R. Mahmud, A. F. Abdou, and H. Pota, "Stability analysis of grid-connected photovoltaic systems with dynamic phasor model," Electron., vol. 8, no. 7, 2019, doi: 10.3390/electronics 8070747 .

[2] M. Luomi, The International Relations of the Green Economy in the Gulf: Lessons from the UAE's State-led Energy Transition, no. May. 2015.

[3] S. Izumi, Y. Karakawa, and X. Xin, "Analysis of small-signal stability of power systems with photovoltaic generators," Electr. Eng., vol. 101, no. 2, pp. 321-331, 2019, doi: 10.1007/s00202019-00778-w.

[4] Z. A. Kamaruzzaman, A. Mohamed, and H. Shareef, "Effect of grid-connected photovoltaic systems on static and dynamic voltage stability with analysis techniques-A review," Univ. Kebangs. Malaysia, vol. 2015, no. 1, pp. 1-8, 2015.

[5] P. Kumar and D. K. Palwalia, "Decentralized Autonomous Hybrid Renewable Power 
Generation," J. Renew. Energy, vol. 2015, pp. 1-18, 2015, doi: 10.1155/2015/856075.

[6] H. M. Sultan, A. A. Zaki Diab, O. N. Kuznetsov, Z. M. Ali, and O. Abdalla, "Evaluation of the impact of high penetration levels of PV power plants on the capacity, frequency and voltage stability of Egypt's unified grid," Energies, vol. 12, no. 3, pp. 1-22, 2019, doi: 10.3390/en12030552.

[7] C. Andersson, J. E. Solem, and B. Eliasson, "Classification of power system stability using support vector machines,” 2005 IEEE Power Eng. Soc. Gen. Meet., vol. 1, no. 2, pp. 650-655, 2005, doi: 10.1109/pes.2005.1489266.

[8] Nagrath Kothari , "Power System Engineering Second Edition“,2008.

[9] P. Venkatesh, B. V. Manikandan, S. C. Raja, and A. Srinivasan, Electrical Power Systems: Analysis, Security and Deregulation. 2012.

[10] A. Jaiswal, M. Kumar, A. Kumar, and R. Kumar, LOAD FLOW AND STABILITY ANALYSIS OF MULTI-MACHINE : 2019. 